\title{
OPTIMIZATION AND VALIDATION OF AN ANALYTICAL METHOD FOR TRANEXAMIC ACID IN WHITENING CREAMS BY RP-HPLC WITH PRECOLUMN DERIVATIZATION
}

\author{
BAITHA PALANGGATAN MAGGADANI, ERNIS OKTAVIANI, YAHDIANA HARAHAP, HARMITA HARMITA*
}

Department of Pharmacy, Faculty of Pharmacy, Universitas Indonesia, Depok, Indonesia. Email: igakadeharmita@gmail.com

Received: 26 September 2019, Revised and Accepted: 17 December 2019

ABSTRACT

Objective: An efficient and selective analytical method with precolumn derivatization using reverse-phase high-performance liquid chromatography (RP-HPLC) was developed for the analysis of tranexamic acid in whitening creams.

Methods: Derivatization was performed using 1\% ninhydrin solution in methanol as a derivation agent to form a colored Ruhemann's purple product. The analytical conditions included the use of a C18 column as the stationary phase and a methanol: acetate (20 mM) buffer at pH 4 (75:25) as the mobile phase, with a flow rate of $0.8 \mathrm{~mL} / \mathrm{min}$ and UV-visible detection at a wavelength of $570 \mathrm{~nm}$.

Results: The average retention time of the tranexamic acid derivative was 5.413 min. The results of the calibration curves were linear, with a correlation coefficient (r) of 0.9993 at a concentration ranging from 8 to $48 \mu \mathrm{g} / \mathrm{mL}$. The recovery was between $99.26 \%$ and $101.77 \%$. The limits of detection and quantification were $1.87 \mu \mathrm{g} / \mathrm{mL}$ and $6.25 \mu \mathrm{g} / \mathrm{mL}$, respectively.

Conclusion: The analytical method developed in this study met the validation requirements and included a simple and efficient derivatization method applicable for the selective analysis of tranexamic acid in whitening creams.

Keywords: Derivatization, Reverse-phase high-performance liquid chromatography, Ninhydrin, Optimization, Tranexamic acid, Validation, Whitening cream.

(C) 2020 The Authors. Published by Innovare Academic Sciences Pvt Ltd. This is an open access article under the CC BY license (http://creativecommons. org/licenses/by/4. 0/) DOI: http://dx.doi.org/10.22159/ijap.2020.v12s1.FF036

\section{INTRODUCTION}

Tranexamic acid, or trans-4-(aminomethyl)cyclohexanecarboxylic acid (Fig. 1), is an antifibrinolytic drug that works by inhibiting the activation of plasminogen into plasmin [1]. In the cosmetic industry, tranexamic acid is also used as an ingredient in whitening creams at a maximum concentration range of $1.5-2 \%$ [2]. However, the excessive use of tranexamic acid on the skin can cause local toxicity, including irritation and allergies [3]. Therefore, the presence of tranexamic acid in whitening cream preparations should be considered so that the concentration does not exceed the specified limit.

Because tranexamic acid does not have a chromophore group, it cannot be measured with a UV-visible detector and requires a derivatization process to increase its detection sensitivity [4]. The previous studies on the derivatization of tranexamic acid reported the use of various derivative agents, such as $0.2 \%$ ninhydrin in methanol [5], phenyl isothiocyanate [6], 2-hydroxynaphthaldehyde in ethanol [7], sodium picryl sulfonate [8], benzene sulfonyl chloride [4], and 2,4-dinitrofluorobenzene [9].

However, among these studies, none analyzed for tranexamic acid in cream preparations because they typically only used the drug tablets or biological fluids as samples. Therefore, in this study, we aimed to optimize and validate an analytical method for detecting tranexamic acid in whitening creams using reverse-phase high-performance liquid chromatography (RP-HPLC) with precolumn derivatization.

\section{MATERIALS AND METHODS}

\section{Instrumentation}

HPLC (LC 20AT, Shimadzu, Japan) equipped with pump, SunFire ${ }^{\mathrm{TM}} \mathrm{C}_{18}$ column, UV-VIS detector SPD-10A (Shimadzu, Japan), manual injector, and data processor (LC-Solution), UV-Vis Spectrophotometry (Jasco V-530), syringe HPLC (SGE, Australia), centrifuge (Labofuge 5100), vortex (Thermo Scientific), micropipette (Eppendorf), sonicator ultrasonic, hotplate (IKA ${ }^{\circledR}$ C-MAG HS 7), pH meters (Eutech Instruments pH 510), and Whatman filter membrane diameter 0.45 .

\section{Chemicals and reagents}

Tranexamic acid (Hunan Dongting Pharmaceutical Co., Ltd.), acetonitrile and methanol HPLC grade (Merck), ninhydrin (Merck), acetic glacial acid (Merck), ammonium acetate (Mallinckrodt $\mathrm{AR}^{\circledR}$ ), distilled water (Ikapharmindo), and whitening cream samples from the market.

\section{Chromatography condition}

Chromatographic separation was carried out using a $\mathrm{C}_{18}$ column as the stationary phase and a methanol-acetate $(20 \mathrm{mM})$ buffer at $\mathrm{pH} 4$ (75:25) as the mobile phase, with a flow rate of $0.8 \mathrm{~mL} / \mathrm{min}$. Chromatographic detection using the UV-visible detector was performed at a wavelength of $570 \mathrm{~nm}$.

\section{Standard and working solution preparation}

The standard stock solution of tranexamic acid $(1000 \mu \mathrm{g} / \mathrm{mL})$ was prepared by dissolving $100 \mathrm{mg}$ of tranexamic acid into a $100 \mathrm{~mL}$ volumetric flask containing $70 \mathrm{~mL}$ of solvent (methanol-aquadest, $90: 10, \mathrm{v} / \mathrm{v}$ ). The mixture was sonicated for $15 \mathrm{~min}$ and then the volume was brought up to the final mark with solvent. The working solution was prepared by diluting the standard stock solution with solvent until a working solution of $200 \mu \mathrm{g} / \mathrm{mL}$ tranexamic acid was obtained. This working solution was then filtered through a $0.45 \mu \mathrm{m}$ membrane filter and stored in the refrigerator until further analysis.

Derivatization was performed by mixing $1 \mathrm{~mL}$ of working solution with $1 \%$ ninhydrin in methanol. The mixture was warmed in a constant temperature bath. The derivatization process was optimized by varying the reaction time, temperature of the reaction, and the ratio between tranexamic acid and ninhydrin. The reaction times were 15 , 20 , and $30 \mathrm{~min}$, the temperatures were $70,80,90$, and $100^{\circ} \mathrm{C}$, and the volumes of ninhydrin were 1 and $2 \mathrm{~mL}$. After the derivatization process was finished, $1 \mathrm{~mL}$ of the finished mixture was transferred into 


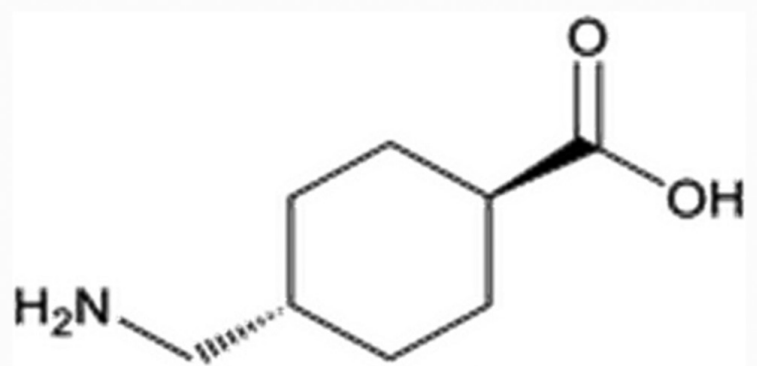

Fig. 1: Structure of tranexamic acid

a $5 \mathrm{~mL}$ volumetric flask and the volume was brought up to the mark with distilled water until a concentration of $40 \mu \mathrm{g} / \mathrm{mL}$ tranexamic acid derivative was obtained. Derivatization of the working solution was done individually before HPLC analysis.

\section{Sample preparation}

Fifty milligrams of the cream sample were accurately weighed and transferred to an Erlenmeyer flask. Five milliliters of solvent were then added to the flask and the solution was heated in an $80^{\circ} \mathrm{C}$ water bath for 1-2 min while shaking vigorously until the cream was completely dissolved. The mixture was then vortexed for $1 \mathrm{~min}$ followed by centrifugation at $4000 \mathrm{rpm}$ for $15 \mathrm{~min}$. The supernatant was then filtered through a $0.45 \mu \mathrm{m}$ membrane filter. A $2 \mathrm{~mL}$ aliquot was then derivatized using the selected optimal conditions and further diluted to obtain a final working concentration. Twenty microliters of the final sample were then injected into the HPLC system and the chromatogram was recorded.

\section{System suitability test}

Twenty microliters of the tranexamic acid derivate were injected into the HPLC system using optimal analysis conditions. The injections were repeated 6 times to ensure a constant peak area. The results of each trial were recorded and the coefficient of variation (CV) was calculated ( $\%$ CV). The $\%$ CV value should be $\leq 2 \%$. The parameters were based on the separation between two adjacent peaks (R), tailing factor, retention time, column efficiency (height equivalent to a theoretical plate [HETP]), and the number of theoretical plates (N).

\section{Validation method}

This method was validated using specific parameters, including selectivity, linearity, limit of detection (LOD), limit of quantification (LOQ), accuracy, and precision. Selectivity was carried out by comparing the chromatogram of a placebo solution with the standard solution around the retention time of the tranexamic acid derivative. There should be no interference with the chromatogram of the placebo/blank solution. The linearity of the method was determined with standard solutions using six concentration points in the range of 8-48 $\mu \mathrm{g}$ / $\mathrm{mL}$. The concentration was obtained by diluting a standard solution of $200 \mu \mathrm{g} / \mathrm{mL}$ tranexamic acid derivative. The calibration curve was plotted between the relationship between the concentration and the area using the least square method. The LOD and LOQ were calculated using statistical calculations with a linear regression calibration curve using the $\mathrm{Sb}$ value, which is equal to the residual standard deviation $(\operatorname{RSD})\left(S_{y / x}\right)$.

Accuracy and precision were examined using a simulation or spiked placebo recovery method. We weighed a number of cream matrixes for each concentration of $80 \%, 100 \%$, and $120 \%$, using $62.5 \mathrm{mg}, 50 \mathrm{mg}$, and $41.7 \mathrm{mg}$, respectively. At each concentration, $5 \mathrm{~mL}$ of a standard solution of $200 \mu \mathrm{g} / \mathrm{mL}$ tranexamic acid were added and then the preparation and derivatization were carried out using the same methods as for the preparation of the cream sample. Accuracy was calculated based on the percentage of recovery, while the precision was calculated by the percentage of the RSD based on three injections at concentrations of $80 \%$ and $120 \%$ and six injections at a concentration of $100 \%$. The percentage of recovery was $98-102 \%$, indicating that the method was accurate. In addition, the $\%$ RSD was $<2$, ensuring the precision of the developed method.

\section{RESULTS}

\section{Optimization of derivatization}

In this study, the derivatization process was performed using ninhydrin, which reacts specifically with the primary amine group of tranexamic acid in the range of pH 5-7 [10]. At the molecular level, two ninhydrin molecules will react with one amine molecule in an organic compound to produce a purple product called Ruhemann's purple [11-13]. Three parameters of the derivatization process were optimized to yield the most optimal process and derivative products. We used reaction times of 15,20 , and $30 \mathrm{~min}$, temperatures of $70,80,90$, and $100^{\circ} \mathrm{C}$, and volumes of ninhydrin of 1 and $2 \mathrm{~mL}$. From our observations, the most optimal derivatization process was carried out by mixing $2 \mathrm{~mL}$ of $200 \mu \mathrm{g} / \mathrm{mL}$ tranexamic acid solution with $1 \mathrm{~mL}$ of $1 \%$ ninhydrin, then heating the solution for $30 \mathrm{~min}$ at $90^{\circ} \mathrm{C}$ using methanol-distilled water $(90: 10, v / v)$ as the solvent. The reaction time for 30 min was considered optimal because it did not show a significant difference when the heating process was continued for a few minutes afterward. The temperature of $90^{\circ} \mathrm{C}$ was chosen as the optimal temperature because higher temperatures were found to yield more derivative products when the temperature increased up to $100^{\circ} \mathrm{C}$, it indicated that the derivative solution was damaged due to boiling. The volume of ninhydrin at $1 \mathrm{~mL}$ was chosen because there was a decrease in the peak area when the volume of ninhydrin was $2 \mathrm{~mL}$. After a series of optimizations, the derivative products were then diluted to obtain the desired concentrations. Compared with the previous method by Natesan et al. [5], this method was considered simpler and produced more stable and precise derivatives during each step of the derivatization.

\section{Optimization of chromatographic conditions}

During the optimization of the chromatographic conditions, two organic solvents, including methanol and acetonitrile, along with various buffers, were used to determine the optimum mobile phase combination. From our analyses, it was concluded that the phosphate buffer provided better peak shapes than the acetate buffer. This was also proven by the previous studies regarding the simultaneous analysis of tranexamic acid and mefenamic acid [5]. Optimal chromatographic separation was achieved using a UV-visible detector with a wavelength of $570 \mathrm{~nm}$, a SunFire ${ }^{\mathrm{TM}} \mathrm{C}_{18}$ column $(250 \times 4.6 \mathrm{~mm}, 5 \mu \mathrm{m})$, a mobile phase of methanol-acetate buffer $(20 \mathrm{mM}) \mathrm{pH} 4.0(75: 25, \mathrm{v} / \mathrm{v})$, and a flow rate of $0.8 \mathrm{~mL} / \mathrm{min}$. The flow rate of $0.8 \mathrm{~mL} / \mathrm{min}$ was chosen because it was shown to produce the largest peak area with the smallest amount of HETP, along with the largest number of theoretical $(\mathrm{N})$ plates. The $\mathrm{pH}$ of 4 for the buffer was adjusted with acetic glacial acid and was chosen according to the pKa of tranexamic acid, which is 4.56 [5]. A slight difference in the $\mathrm{pH}$ and $\mathrm{pKa}$ was expected to maintain the molecular form of the tranexamic acid derivatives. In this method, the addition of the organic solvents accelerated the retention time of the analyte. The use of the mobile phase above produced the largest peak area and the shortest retention time compared with other mobile phase combinations. The chromatograms of the standard solutions of the tranexamic acid derivatives under the optimal analytical conditions are shown in Fig. 2, with data from the mobile phase optimization shown in Table 1.

\section{System suitability test}

The suitability test aimed to ensure that the analytical method was not influenced by variations in the existing equipment or the technical analysis used, thus the operational system's effectiveness was guaranteed and it provided results that were consistent with the initial objectives of the analysis. After six repeated injections, the \% RSD for the analytical method of the tranexamic acid derivative was $0.33 \%$. From the data analysis, the method we developed met the system suitability test requirements because it had a $\%$ RSD value of no more than $2 \%$. 


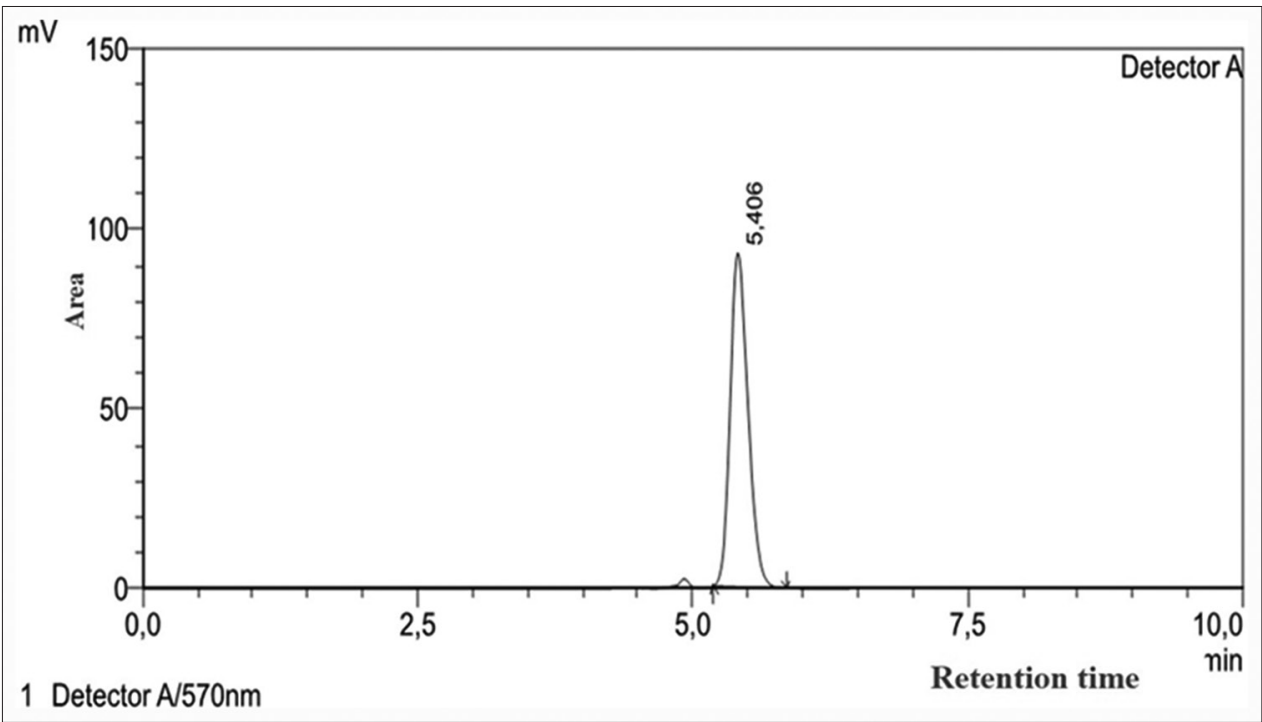

Fig. 2: Chromatogram of the tranexamic acid derivative standard

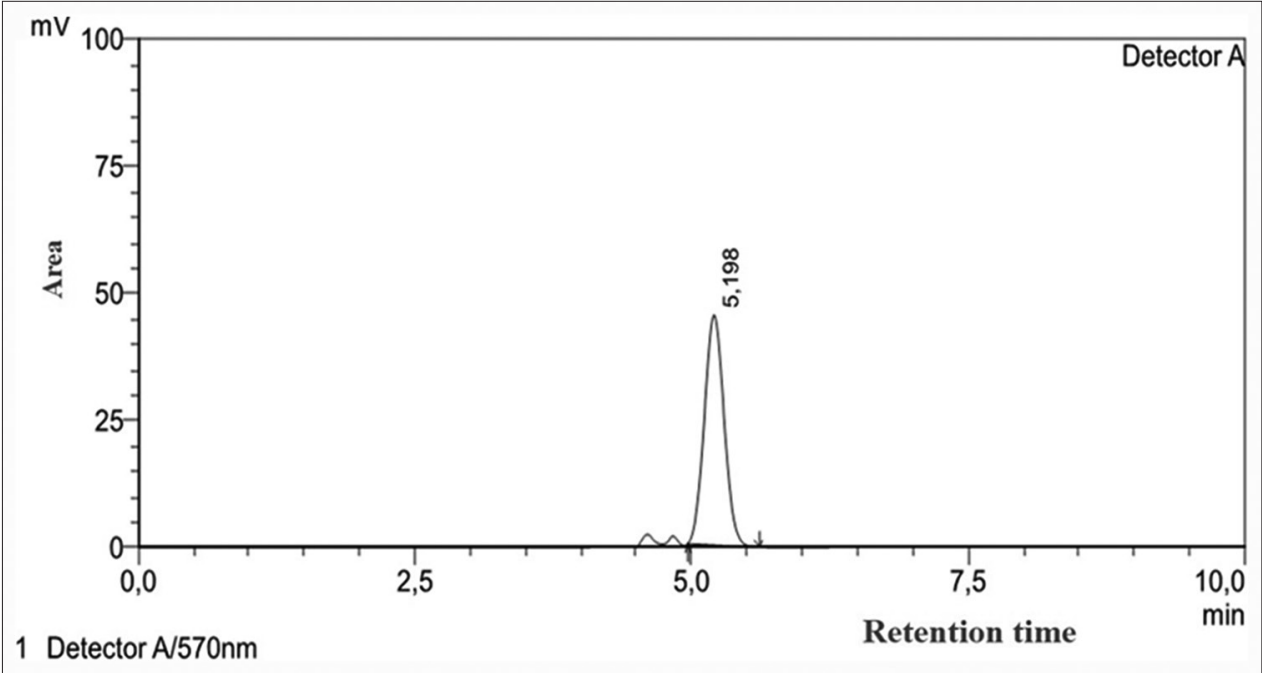

Fig. 3: Chromatogram of a cream sample on the market

Table 1: The results of mobile phase optimization with a flow rate of $1 \mathrm{~mL} / \mathrm{min}$

\begin{tabular}{lllllll}
\hline Mobile phase & Ratio $(\mathbf{v} / \mathbf{v})$ & Area $(\boldsymbol{\mu V} / \mathbf{s})$ & $\begin{array}{l}\text { Retention time } \\
\text { (minutes) }\end{array}$ & $\begin{array}{l}\text { Tailing } \\
\text { factor }(\mathbf{T f})\end{array}$ & HETP $(\mathbf{m m})$ & Theoretical plate $(\mathbf{N})$ \\
\hline Methanol-20 mM acetic buffer pH 4 & $75: 25$ & 872,658 & 4.891 & 1.277 & 23.572 & 6364 \\
Acetonitrile-100 mM acetic buffer pH 5 & $25: 75$ & 605,948 & 11.573 & 1.277 & 12.567 & 11.936 \\
Acetonitrile-10 mM pH 3.6 & $35: 65$ & 471,294 & 12.851 & 1.871 & 23.017 & 6517 \\
\hline
\end{tabular}

HETP: Height equivalent to a theoretical plate

\section{Validation method}

\section{Selectivity}

Selectivity assessment was performed by evaluating the chromatograms of the placebo, standard, and cream sample solutions. Based on the results of the analysis, the chromatogram of the standard solution had a good correlation with the sample, and the chromatogram of the placebo solution showed a clean chromatogram with no interference from other compounds around the retention time of the tranexamic acid derivative. This demonstrated that the placebo cream did not contain compounds that could react with ninhydrin; therefore, this method was concluded to be selective. The chromatograms for each solution are shown in Figs. 2 and 3.

\section{Linearity}

From the six concentrations of the standard solutions in the range of $8-48 \mu \mathrm{g} / \mathrm{mL}$, a linear regression equation was obtained, $\mathrm{y}=23929 \mathrm{x}$ +8927.1 with a correlation coefficient (r) of 0.9993. From the results of the analysis, we considered that the calibration curve had met the linearity test requirements. The linear regression data are shown in Table 2 and the calibration curve is shown in Fig. 4.

\section{LOD and LOQ}

The LOD and LOQ were calculated from the results of the linear regression and calibration curves that were obtained. The LOD and LOQ were very important because they were used to set the lowest limit of 
Table 2: Data of the calibration curve, LOD, and LOQ

\begin{tabular}{llllll}
\hline Concentration $(\mu \mathrm{g} / \mathrm{mL})$ & Peak area $(\boldsymbol{\mu V} / \mathbf{s})$ & $\mathbf{S}(\mathbf{y} / \mathbf{x})^{2}$ & $\mathbf{S}(\mathbf{y} / \mathbf{x})$ & $\mathbf{L O D}(\boldsymbol{\mu g} / \mathbf{m L})$ & $\mathbf{L O Q}(\boldsymbol{\mu g} / \mathbf{m L})$ \\
\hline 8 & 189,060 & $223,886,426$ & 14,962 & 1.88 & \\
16 & 377,509 & & & \\
24 & 564,184 & & & \\
32 & 730,556 & & & \\
40 & 957,188 & & & \\
48 & $1,147,997$ & & & \\
$\mathrm{~N}=6$ & $\mu(\mathrm{y}-\mathrm{yi})^{2}=895,545,704.9$ & & & \\
\hline
\end{tabular}

LOD: Limit of detection, LOQ: Limit of quantification

Table 3: Data obtained from accuracy and precision testing

\begin{tabular}{|c|c|c|c|c|c|c|}
\hline Real concentration $(\mu \mathrm{g} / \mathrm{mL})$ & Counted peak area $(\mu \mathrm{V} / \mathrm{s})$ & Counted concentration $(\mu \mathrm{g} / \mathrm{mL})$ & SD & CV (\%) & Recovery (\%) & Average (\%) \\
\hline \multirow[t]{3}{*}{32} & 229,117 & 31.93 & \multirow[t]{3}{*}{0.2280} & \multirow[t]{3}{*}{0.71} & 99.79 & \multirow[t]{3}{*}{99.93} \\
\hline & 228,538 & 32.23 & & & 100.70 & \\
\hline & 227,986 & 31.78 & & & 99.30 & \\
\hline \multirow[t]{6}{*}{40} & 289,852 & 39.86 & \multirow[t]{6}{*}{0.3846} & \multirow[t]{6}{*}{0.95} & 99.64 & \multirow[t]{6}{*}{101.06} \\
\hline & 289,971 & 40.71 & & & 101.77 & \\
\hline & 292,877 & 40.70 & & & 101.76 & \\
\hline & 289,802 & 40.05 & & & 100.14 & \\
\hline & 292,544 & 40.10 & & & 100.26 & \\
\hline & 293,032 & 40.66 & & & 101.64 & \\
\hline \multirow[t]{3}{*}{48} & 353,489 & 48.49 & \multirow[t]{3}{*}{0.4458} & \multirow[t]{3}{*}{0.93} & 101.01 & \multirow[t]{3}{*}{100.31} \\
\hline & 353,671 & 47.64 & & & 99.26 & \\
\hline & 354,847 & 48.32 & & & 100.67 & \\
\hline
\end{tabular}

$\mathrm{CV}$ : Coefficient of variation

Table 4: Quantification of tranexamic acid amounts in a whitening cream sample on the market

\begin{tabular}{llllll}
\hline Sample & Sample weight $(\mathbf{m g})$ & Peak area $(\boldsymbol{\mu V} / \mathbf{s})$ & Counted concentration $(\boldsymbol{\mu g} / \mathbf{m L})$ & Amount $(\%)$ & Average amount $(\%)$ \\
\hline $\mathrm{X}$ & 50 & 511,156 & 21.73 & 1.09 & 1.08 \\
& & 507,759 & 21.59 & 1.08 & \\
& 504,417 & 21.45 & 1.07 & \\
\hline
\end{tabular}

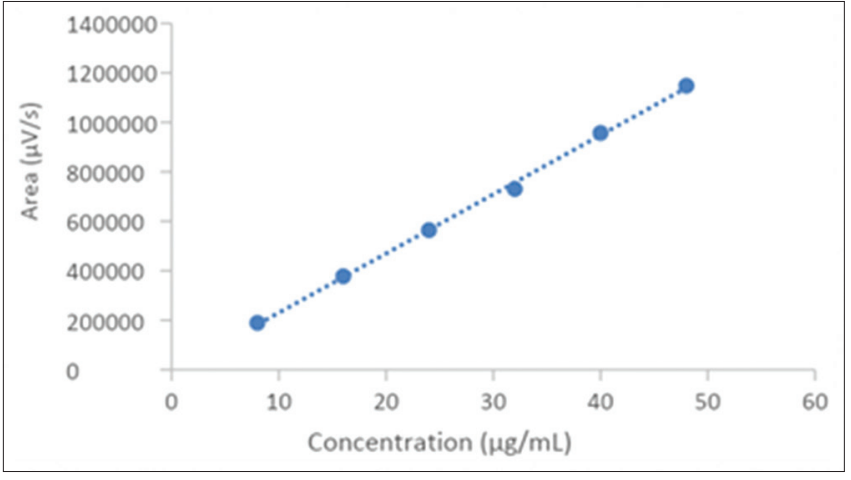

Fig. 4: Calibration curve of the tranexamic acid derivative LOD and LOQ

the substance concentration that could still be analyzed accurately and precisely. Accordingly, a given method is said to be more sensitive if it has a smaller LOD and LOQ value. From the results of the analysis, the LOD and LOQ obtained were $1.88 \mu \mathrm{g} / \mathrm{mL}$ and $6.25 \mu \mathrm{g} / \mathrm{mL}$, respectively. The full LOD and LOQ sets of data are shown in Table 2.

\section{Recovery and system precision}

Recovery was performed to ensure the accuracy and applicability of the analytical method. The accuracy and recovery were considered to meet the requirements if the values were in the range of $98-102 \%$. The recovery was tested at three levels of concentration $(80 \%, 100 \%$, and $120 \%$ ) by the standard addition method. The requirement for precision is a $\% \mathrm{CV} \leq 2 \%$ [14]. Based on the experimental results, the average recovery percentage obtained for the standard solutions of the tranexamic acid derivatives with concentrations of $80 \%, 100 \%$, and $120 \%$ was $99.93 \%, 101.06 \%$, and $100.31 \%$. The coefficient variation $(\% \mathrm{CV})$ values obtained were $0.71,0.95$, and 0.93 , respectively. From these data, it was concluded that the method for analyzing tranexamic acid in cream preparations met the proposed criteria. The complete data regarding the accuracy and precision testing are shown in Table 3.

Application of the analytical method to cream samples

This method was optimized for the quantification of tranexamic acid in cream samples. The results of the quantification of a whitening cream sample on the market showed that the tranexamic acid amount contained was $1.08 \%$. This amount does not exceed the set limit for cosmetics, which is 1.5-2\% [2]. The amount determined was calculated based on the linear regression equation obtained from our analysis. From the results of the analysis, it was concluded that the method in this study was applicable for the analysis of tranexamic acid in whitening creams. The quantification data are shown in Table 4.

\section{DISCUSSION}

The aim of this study was to develop an efficient and effective analytical method for the analysis of tranexamic acid, specifically in cream cosmetics. The use of tranexamic acid in cosmetics was proven to be as effective as hydroquinone for the treatment of melasma, a common disorder characterized by hyperpigmentation of the skin [15]. Therefore, valid analytical methods for the analysis of tranexamic acid are important to ensure the quality and quantity of tranexamic acid in these preparations. Accordingly, the analytical method should be efficient, reliable, applicable, fast, and economical. Tranexamic acid does not have p-electrons where it could act as a fluorophore or chromophore. Hence, it cannot be measured using a UV-visible detector directly and derivatization is needed to obtain a chromophore or fluorophore for 
analysis using an HPLC system with a UV-visible detector. The previous studies have reported the analysis of tranexamic acid using HPLC UV detection methods and different derivatization reagents, including ninhydrin in methanol [5], phenyl isothiocyanate [6], sodium picryl sulfonate [8], and 2-hydroxynaphthaldehyde [7]. However, none of those studies reported the analysis of tranexamic acid in cream formulations. Therefore, in this study, we develop an analytical method for analyzing tranexamic acid in cream formulations. Derivatization was carried out using a $1 \%$ ninhydrin solution in methanol. Ninhydrin was selected as the derivative agent because it produced the shortest retention time of the derivatives studied and generated a more straightforward preparation method compared with other derivatives. The derivatization process described here only needs $30 \mathrm{~min}$ and is a single heating process, thus making it fast and straightforward. In addition, the derivatized products were stable during analysis, and the total running time was $<6 \mathrm{~min}$. The developed method was successfully applied for the detection and quantification of tranexamic acid in cosmetic cream products.

\section{CONCLUSION}

In this study, we developed an economical, simple, fast, and selective analytical method for analyzing tranexamic acid in whitening creams using RP-HPLC. This method was proven to meet the validation requirements, which included selectivity, linearity, LOD and LOQ accuracy, and precision. A precolumn derivatization process using $1 \%$ ninhydrin was needed to increase the detection of tranexamic acid and yielded sharp peaks with a short analysis time of $<6 \mathrm{~min}$. This method is considered suitable for quality control analysis in industry because it was found to be very sensitive and required only a small amount of sample.

\section{ACKNOWLEDGMENTS}

This study was supported by TADok Project No: NKB-0095/UN2.R3.1/ HKP.05.00/2019 granted by Universitas Indonesia. The funder had no role in study design, data collection and analysis, dicision to publish or preparation of manuscript.

\section{CONFLICTS OF INTEREST}

All authors have none to declare.

\section{REFERENCES}

1. Zhou XD, Tao LJ, Li J, Wu LD. Do we really need tranexamic acid in total hip arthroplasty? A meta-analysis of nineteen randomized controlled trials. Arch Orthop Trauma Surg 2013;133:1017-27.

2. Dunn CJ, Goa KL. Tranexamic acid: A review of its use in surgery and other indications. Drugs 1999;57:1005-32.

3. Reynolds JE. Martindale: The Extra Pharmacopoeia. Great Britain: Royal Pharmaceutical Society; 1996.

4. Ashfaq M, Aslam A, Mustafa G, Danish M, Nazar MF, Asghar MN Derivatization/chromophore introduction of tranexamic acid and its HPLC determination in pharmaceutical formulations. J Assoc Arab Univ Basic Appl Sci 2015;17:51-56.

5. Natesan $S$, Thanasekaran D, Krishnaswami V, Ponnusamy C. Improved $\mathrm{Rp}-\mathrm{Hplc}$ method for the simultaneous estimation of tranexamic acid and mefenamic acid in tablet dosage form. Pharm Anal Acta 2011;2:115.

6. Hadad GM, El-Gindy A, Mahmoud WM. Optimization and validation of an HPLC-UV method for determination of tranexamic acid in a dosage form and in human urine. Chromatographia 2007;66:311-17.

7. Khuhawar MY, Rind FM. HPLC determination of tranexamic acid in pharmaceutical preparations and blood. Chromatographia 2001;53:709-11.

8. Nojiri S, Uehara S, Hagiwara T, Nishijima M. High performance liquid chromatographic determination of aspartic acid, taurine, and tranexamic acid by precolumn derivatization using sodium picrylsulfonate. Tokyo Toritsu Eisei Kenkyusho Kenkyu Nenpo 1995;46:58-61.

9. Patil R, Ahmed AK, Firke S, Pawar D. RP-HPLC PDA analysis of tranexamic acid in bulk and tablet dosage form. Anal Chem Lett 2017;7:813-21.

10. Moore S, Stein WH. Photometric ninhydrin method for use in the chromatography of amino acids. J Biol Chem 1948;176:367-88.

11. Ramminger U, Nickel U, Geide B. Enhancement of an insufficient dyeformation in the ninhydrin reaction by a suitable post treatment process. J Forensic Sci 2001;46:288-93.

12. Friedman M. Applications of the ninhydrin reaction for analysis of amino acids, peptides, and proteins to agricultural and biomedical sciences. J Agr Food Chem 2004;52:385-406.

13. Sahani S, Jain V. A novel reversed-phase high-performance liquid chromatography method for simultaneous estimation of drotaverine hydrochloride, ethamsylate, and tranexamic acid in tablet dosage form. Asian J Pharm Clin Res 2018;11:121-5.

14. Ebrahimi B, Naeini FF. Topical tranexamic acid as a promising treatment for melasma. J Res Med Sci 2014;19:753-7.

15. Kausar R, Akhtar N. Evaluation of depegmenting and antierythemic effects of cosmetic emulgels containing raspberry fruit extract on human cheek skin. Int J Pharm Pharm Sci 2016;9:236-8. 